Article

\title{
Compromise between Short- and Long-Term Financial Sustainability: A Hybrid Model for Supporting R\&D Decisions
}

\author{
Kao-Yi Shen \\ Department of Banking \& Finance, Chinese Culture University (SCE), Taipei 11114, Taiwan; \\ atrategy@gmail.com; Tel.: +886-2-2700-5858 (ext. 8676) \\ Academic Editors: Xiang Li, Jian Zhou, Hua Ke and Xiangfeng Yang \\ Received: 16 January 2017; Accepted: 22 February 2017; Published: 4 March 2017
}

\begin{abstract}
The debate of "short-termism" has gained increasing interests from various fields, ranging from management to economics; it mainly concerns the decisions or actions taken by businesses that might yield short-term returns at the cost of long-term value or sustainability. Previous studies have highlighted this dilemma faced by managers, mainly from the pressure of capital markets or short-sighted shareholders who crave for immediate financial outcomes; intelligent decision aids that can compromise between the short- and long-term financial sustainability, based on a company's policy, are highly needed. Therefore, the aim of this study is to develop a multiple-rule-based hybrid decision model to support management teams on prioritizing new R\&D projects, considering the financial prospects in dual timeframes (i.e., short- and long-term) for sustainability. Furthermore, in the presence of business uncertainty and the limited knowledge of managers on new projects, the intuitionistic fuzzy technique is incorporated. A case of selecting new R\&D projects for an IC design company is illustrated using the proposed approach, and the financial data from a group of public-listed IC stocks from Taiwan are inducted to form the decision model. The findings not only support the IC design company to select new projects but also provide business insights to facilitate the understandings of this controversial issue in managerial practice.
\end{abstract}

Keywords: multiple criteria decision-making (MCDM); rough set theory (RST); dominance-based rough set approach (DRSA); intuitionistic fuzzy set (IFS); financial performance (FP); short-termism

\section{Introduction}

Over the past few decades, the debate of "short-termism" or "business myopia" has drawn rising interests from both academia and practice, which argues that business often takes the course of actions that are not the best interests over the long run for pursuing short-term gains. The economic aspect, factors such as the pressure from capital markets or the performance measurement mechanism, has been regarded as the key source for this phenomenon [1,2]. Laverty [3,4] further developed a theoretical framework and claimed that this dilemma should also be analyzed along with the other two aspects: individual and organizational perspectives. The present work agrees with the theoretical framework of Laverty's and presumes that the pressure from financial markets and a company's policy both have strong influences on managers while making critical decisions that require considering both the short- and long-term prospects.

In the research of short-termism, two topics related to firms' financial performance (FP) have seen growing number of studies: (1) the frequency of financial reporting [5]; and (2) the influence of short-termism on firm innovations [6]. The former doubts the costs and benefits of increased frequency of financial reporting (e.g., quarterly or semiannual statements) to the capital market, and the latter one examines the influence of capital markets on firms' research and development (R\&D) behavior. 
Although the necessity of frequent reporting is still controversial in accounting and finance research, in practice, certain regional legislatives-such as the European Union Parliament and the authority in Singapore-have exempted the mandatory quarterly reporting for small-to-mid size companies [7]. In the context of innovations, the impact of "short-termism" on curbing the R\&D funding of firms to establish long-term competitive advantages has also been widely examined. The findings from several major markets (such as in the US and UK) inclined to acknowledge the influence of "short-termism" on firms' R\&D spending [8,9], which imply that firms do suffer from the capital markets' pressures to seek for short-term financial outcomes.

A substantial body of research have documented the influence of "short-termism" to business on making decisions; however, little progress have been seen on how to assist managers in tackling the predicament in making transparent and circumspect decisions. Although nearly everyone would agree that sustainability is the ultimate goal of businesses, the existence of "short-termism" might compel managers to undertake inferior strategies or actions. As a result, the central purpose of this study is to develop an insightful decision support model, considering both the short- and long-term financial prospects for decision aids.

To illustrate the proposed hybrid approach, a case of evaluating new R\&D projects for an IC design company is discussed. The assessment of new R\&D projects requires the experience and knowledge from experts; nevertheless, experts or DMs sometimes might not have full confidence on judging the potential of a project on a particular criterion. Therefore, the intuitionistic fuzzy set (IFS) [10-12] technique is incorporated to reserve the hesitancy of DMs on making judgments.

The present study hopes to facilitate the understandings of how to form a transparent decision model considering the influences in both short- and long-term. Its novelty and plausible contributions are summarized as follows: (1) induct understandable decision rules (knowledge) to form a transparent decision model from historical data; (2) propose a novel approach that integrates the learned knowledge in the short- and long-term with the hesitant judgments from DMs; and (3) guide a company to select and improve (enhance) its R\&D projects to be in line with its own financial policy.

The remainder of this paper is structured as follows: Section 2 introduces the rough machine learning approach in multiple criteria decision-making (MCDM) research and shows how to form the hybrid decision model with defined research steps. A case of new R\&D project evaluation of an IC design company is illustrated and discussed in Sections 3 and 4, respectively. Section 5 concludes this study.

\section{Preliminary and Multidisciplinary Methods for the Hybrid Model}

This hybrid model comprises of four key parts: (1) a rough set based machine-learning mechanism; (2) a bipolar framework that filters the involved positive and negative decision rules in the two timeframes; (3) the intuitionistic fuzzy set (IFS) evaluation; and (4) a performance aggregator for integrating the final evaluations. The hybrid decision model's overall structure is illustrated in Figure 1, and the details of each part are explained in the following subsections.

\subsection{Rough Machine Learning Mechanism}

The first part leverages the machine learning capability of rough set theory (RST)—proposed by Pawlak [13] — which is capable of discerning logical relations by analyzing the vagueness and impreciseness of data. It was further enhanced to consider the preferential characteristic of attributes of a data set and termed as the dominance-based rough set approach (DRSA) [14-19], which is acknowledged as more suitable to deal with decision-making problems than the original RST.

In the present study, the DRSA is adopted to learn logic from the financial changes of IC design companies, which associates the key financial ratios' relative performances (of a company) at time $t$ with its subsequent outcome at time $t+1$. This rough machine learning mechanism explores the logical (consequential) relations of the key performance ratios' changes that may lead to superior or inferior financial prospects in both the short- and long-term periods. 


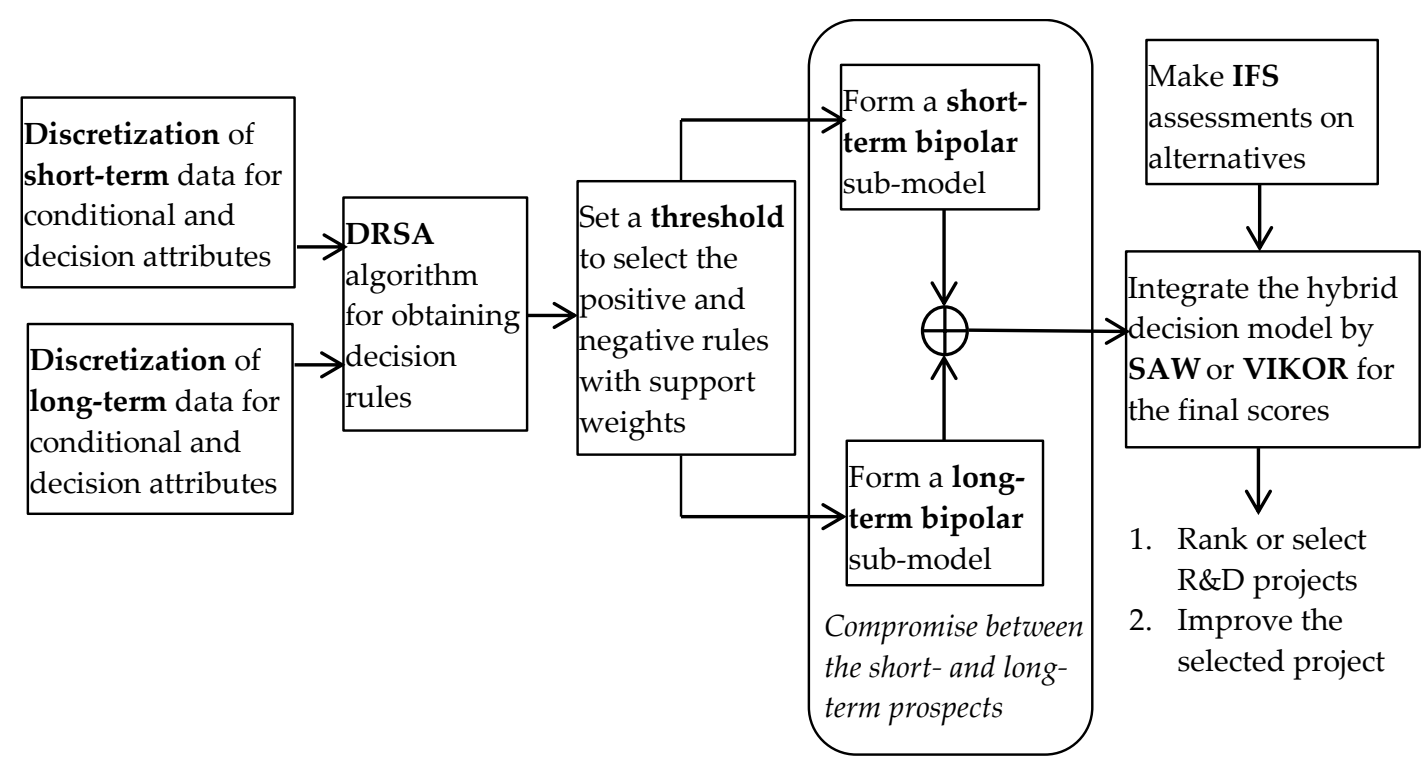

Figure 1. Research framework of the hybrid decision model.

To induct rough logical relations, data should be defined as an information system (IS), where $I S=(U, Q, V, f)$. In a DRSA IS, $U$ is a finite set of universe; $Q$ is a finite set of $k$ attributes (i.e., $Q=\left\{q_{1}, q_{2}, \ldots, q_{i}, \ldots, q_{k}\right\}$ ); $V$ is the value domain of attributes (i.e., $V=\cup_{q \in Q} V_{q}$ ); and $f$ denotes a total function (i.e., $f: U \times Q \rightarrow V$ ), where $f\left(x, q_{i}\right) \in V_{q_{i}}$ for each $x \in U$ and $q_{i} \in Q$. The attributes comprise of conditional attributes $C$ and a decision attribute $D$ for a typical MCDM problem. To learn the logical consequences of financial changes in this study, the condition and decision attributes are further denoted as $C^{t}$ and $D^{t+1}$ at time periods $t$ and $t+1$, respectively.

Assume that $U$ comprises of $n$ alternatives, a complete outranking relation on $U$ can be defined as $\succeq_{q}$ with respect to a criterion $q \in Q$. If $x \succeq_{q} y$ for $x, y \in U$, then it denotes that " $x$ is not worse than $y$ on criterion $q^{\prime \prime}$. Decision attribute $d \in D$ divides $U$ into a finite number of decision classes (DCs), i.e., $D=\left\{d_{h}^{t+1}: d_{1}^{t+1}, d_{2}^{t+1}, \ldots, d_{m}^{t+1}\right\}$ for $h=1,2, \ldots, m$. For each $x, y \in U$, object falls in only one decision class $d_{h}^{t+1}\left(d_{h}^{t+1} \in D\right)$. The general classes ( $\left.C l s\right)$ in DRSA are further categorized as two types: the downward and upward union classes, defined in Equations (1) and (2):

$$
\begin{aligned}
& { }^{\leq} C l_{\alpha}=\underset{\beta \leq \alpha}{\cup} C l_{\beta} \\
& \geq C l_{\alpha}=\cup_{\beta \geq \alpha} C l_{\beta}
\end{aligned}
$$

In Equation (1), $\mathrm{Cl}_{\alpha}$ indicates the class $(\mathrm{Cl})_{\alpha} ;{ }^{\geq} \mathrm{Cl}_{\alpha}$ denotes the downward union that all the $\mathrm{Cls}$ in it are inferior to $C l_{\alpha}$; and, similarly, $\geq C l_{\alpha}$ denotes the upward union. The conditional attributes in $C$ can be used to classify DCs by the dominance relations. For any partial set $P$ of $C(P \subseteq C)$ and $x, y \in U$, $x$ dominates $y$ regarding $P$ can be denoted by $x D_{P} y$, which denotes that $x P$-dominates $y$. One point is worth noting here: the dominating and dominated relations in this study are two folds, one is for the conditional attributes at time $t$, and the other one is for the decision attribute at time $t+1$. A set of objects (in $U$ ) that dominates $x$ at $t+1$ is termed as the $P$-dominating set in Equation (3), and a set of objects dominated by $x$ the $P$-dominated set (in Equation (4)):

$$
\begin{aligned}
& { }^{+} D_{P}^{t+1}(x)=\left\{y \in U: y D_{P}^{t+1} x\right\} \\
& { }^{-} D_{P}^{t+1}(x)=\left\{y \in U: x D_{P}^{t+1} y\right\}
\end{aligned}
$$


The objects in ${ }^{+} D_{P}^{t+1}(x)$ and ${ }^{-} D_{P}^{t+1}(x)$ are used to represent the upward and downward unions of DCs, respectively. For brevity, only the upward union is explained (for identifying positive financial changes) hereafter, and the downward union can be reasoned similarly. The $P$-lower and $P$-upper approximation of ${ }^{+} D_{P}^{t+1}(x)$ are defined in Equations (5) and (6):

$$
\begin{gathered}
\underline{P}\left({ }^{+} D_{P}^{t+1}(x)\right)=\underline{P}\left({ }^{\geq} C l_{\alpha}\right)=\left\{x \in U:{ }^{+} D_{P}^{t+1}(x) \subseteq{ }^{\geq} C l_{\alpha}\right\} \\
\bar{P}\left({ }^{+} D_{P}^{t+1}\right)=\bar{P}\left({ }^{\geq} C l_{\alpha}\right)=\left\{x \in U:{ }^{+} D_{P}^{t+1} \cap{ }^{\geq} C l_{\alpha} \neq \varnothing\right\}
\end{gathered}
$$

$\underline{P}\left(\geq C l_{\alpha}\right)$ denotes a set, for all the objects in $U$ that are included in the upward union ${ }^{\geq} C l_{\alpha}$ with certainty $\left(\bar{P}\left(\geq C l_{\alpha}\right)\right.$ the uncertain ones), whereas all objects have at least the same or superior evaluation regarding all attributes in $P(P \subseteq C)$. On the other side, $\bar{P}\left(\geq C l_{\alpha}\right)$ indicates the set of all the objects in $U$ that might belong to the upward union ${ }^{\geq} \mathrm{Cl}_{\alpha}$. In other words, some of the objects in $U$ that belong to ${ }^{\geq} \mathrm{Cl}_{\alpha}$ are with uncertainty or ambiguity. The boundary region that represents the doubtful region for the objectives that might be included in the upward union ${ }^{\geq} C l_{\alpha}$, defined as: $B n_{P}=\bar{P}\left({ }^{\geq} C l_{\alpha}\right)-\underline{P}\left({ }^{\geq} C l_{\alpha}\right)$.

The requirement of the dominance principle by DRSA in this model is: if an object $x$ dominates object $y$ on a partial condition-attribute set $P$ at time $t$, then the object $x$ should also dominate $y$ on the decision attribute at time $t+1$; the dominance relation that holds at both time periods $t$ (for conditional attributes) and $t+1$ (for a decision attribute) would thus yield a group of consequential logic in the form of decision rules. The objects that comply with the dominance principle are called consistent; otherwise, inconsistent. The accuracy of approximation of ordered classes $\geq \mathrm{Cl}_{\alpha}$ regarding a set of criteria $P \subseteq C$ is defined as $\alpha_{P}\left({ }^{2} C l_{\alpha}\right)$ in Equation (7), where $|\cdot|$ denotes the cardinality of a set. In addition, the approximation quality of every $P \subseteq C$ for ordinal DCs with respect to a set of attributes $P$ can be defined by Equation (8).

$$
\begin{gathered}
\alpha_{P}\left({ }^{\geq} C l_{\alpha}\right)=\frac{\left|\underline{P}\left(\geq C l_{\alpha}\right)\right|}{\left|\bar{P}\left(\geq C l_{\alpha}\right)\right|} \\
\gamma_{P}(C l)=\left|U-\left(\underset{\alpha \in\{2, \ldots, n\}}{\cup} B n_{P}\left({ }^{\geq} C l_{\alpha}\right)\right)\right| /|U|
\end{gathered}
$$

Each minimal subset $P$ that could satisfy $\gamma_{P}(\mathrm{Cl})=\gamma_{C}(\mathrm{Cl})$ is a REDUCT of the $I S$, and the intersection of all REDUCTs represent the indispensable attributes to maintain the quality of approximation, termed a CORE set. The CORE-attribute-based MCDM approach has been applied in several studies [20-24], which has gained rising interests in MCDM research.

In the first part of this hybrid model, using the rough dominance-based approximation, a set of decision rules can be inducted as "IF antecedent THEN consequence", which can support DMs to identify (learn) the changes of financial patterns from historical data. This approach is also termed multiple-rules-based decision making (MRDM), which is an emerging field in the research of MCDM.

In addition, the objects (instances or observations) that are consistent with the dominance principle in a rule are termed as the support of a rule. To proceed the rough machine learning in this part, the required steps are as follows:

- $\quad$ Step 1: Define and discretize the conditional and decision attributes. To form the subsequent bipolar framework, $d_{h}^{t+1}$ is defined only in three DCs: positive (POS), neutral (NEU), and negative $(N E G)\left(C l_{P O S} \succ C l_{N E U} \succ C l_{N E G}\right)$. The details of discretization in the case study will be explained in Section 4.

- Step 2: Associate each alternative's conditional attributes' values at time $t$ with its decision attribute at time $t+1$. The step of associations can form a set of DRSA IS.

- Step 3: Divide all the available data from Step 2 into two groups: the training and testing sets. Once a training set's classification result is regarded as acceptable, an untouched testing set will be used to examine it. The training set is used to induct the decision rules associated with the 
positive and negative DCs, termed as the positive and negative rules, to form the associated bipolar model.

\subsection{Bipolar Framework}

After obtaining the positive and negative decision rules, the bipolar framework is structured-to select the covered positive and negative rules from Step 3-by a DM selected threshold [25,26]. The threshold $(\Omega)$ is defined as the minimal or required percentage of the instances (objects or alternatives) that satisfy the dominance relation of DRSA in the two groups (i.e., the positive and negative groups), which are defined in Equations (9) and (10).

$$
\begin{aligned}
& \left|O_{P O S}\right| / \varepsilon \geq \Omega \\
& \left|O_{N E G}\right| / \eta \geq \Omega
\end{aligned}
$$

In Equations (9) and (10), $|\cdot|$ denotes the cardinality of a set; $\varepsilon$ and $\eta$ are the total numbers of the $P O S$ and NEG instances (or alternatives) in the DRSA IS; thus, the required numbers of the covered objectives in the two groups can be found as $\left|O_{P O S}\right|$ and $\left|O_{N E G}\right|$. All the learned positive and negative rules are then ranked by the number of supports, from high to low, named as: $R u l e_{i}^{P O S}$ (for $i=1, \ldots, k$, $\ldots, n$ ) and $R u l e_{j}^{N E G}$ (for $j=1, \ldots, l, \ldots, m$ ); assuming that there are $n$ and $m$ rules in the positive and negative groups, respectively. Furthermore, the support number for the two group of rules are denoted as $S_{i}^{P O S}$ and $S_{j}^{N E G}$. Take the selected rules in the positive group for example, to satisfy Equation (11), $R u l e_{1}^{P O S}$ (with the highest supports in the positive rules), .., Rule $e_{k \mathrm{th}}^{P O S}$ should be selected in the bipolar model. Similarly, Rule $e_{1}^{N E G}, \ldots$, Rule $_{l \mathrm{th}}^{N E G}$ that satisfy Equation (12) should also be selected in the bipolar model.

$$
\begin{aligned}
& \sum_{1}^{k \text { th }} S_{i}^{P O S} \geq\left|O_{P O S}\right| \\
& \sum_{1}^{l \text { th }} S_{j}^{N E G} \geq\left|O_{N E G}\right|
\end{aligned}
$$

In the bipolar model, each rule is regarded as a context, and termed as the positive or negative criteria. The raw support weights for the two group of new criteria can thus be defined as Equations (13) and (14), and they should be normalized to sum up to unity in a bipolar model.

$$
\begin{gathered}
w_{i}^{P O S}=S_{i}^{P O S} / \sum_{1}^{k} S_{i}^{P O S} \\
w_{j}^{N E G}=S_{j}^{N E G} / \sum_{1}^{l} S_{j}^{N E G}
\end{gathered}
$$

With the obtained rules and support weights, the required steps in forming a rough rules based bipolar model are as follows:

- $\quad$ Step 4: Define a threshold $\Omega$ to select the covered positive and negative rules (refer to Equations (9) and (10)).

- Step 5: Rank the positive and negative rules (new criteria) based on their supports, and calculate their raw support weights according to Equations (9)-(14); the raw support weights should be normalized to sum up to unity as the normalized support weights in a bipolar model.

\subsection{Intuitionistic Fuzzy Set Evaluation}

Proposed by Atanassov [10,27], IFS not only denotes the degree of belongingness, but also the degree of un-belongingness, which is capable and suitable for DMs to indicate their judgments with 
certain degree of hesitancy [28]. Following the definitions of IFS [28], $X$ is assumed to be a nonempty set; two mappings on $X$ are denoted in Equations (15) and (16) as a membership and a non-membership function for $X$.

$$
\begin{aligned}
\mu_{\widetilde{I}} & : X \rightarrow[0,1] \\
x & \mapsto \mu_{\widetilde{I}}(x) \\
v_{\widetilde{I}} & : X \rightarrow[0,1] \\
x & \mapsto v_{\widetilde{I}}(x)
\end{aligned}
$$

Since Equations (15) and (16) denote the membership and non-membership functions of $X$, $0 \leq \mu_{\widetilde{I}}(x)+v_{\widetilde{I}}(x) \leq 1$, and $1-\left(\mu_{\widetilde{I}}(x)+v_{\widetilde{I}}(x)\right)=h_{\widetilde{I}}(x)$; in which, $h_{\widetilde{I}}(x)$ denotes the degree of hesitancy. In the hybrid model, the antecedents in each new criterion (i.e., decision rule) of a new alternative require the judgments of DMs, and two operations of the IFS evaluations in the bipolar model are used: (1) the addition; and (2) the product of an IFS and a real number that denotes the normalized support weight from Step 5. The aforementioned operations of the IFS are shown in Equations (17) and (18) [28].

$$
\begin{aligned}
\widetilde{A}+\widetilde{B} & =\left\{\left\langle x, \mu_{\widetilde{A}}(x)+\mu_{\widetilde{B}}(x)-\mu_{\widetilde{A}}(x) \times \mu_{\widetilde{B}}(x), v_{\widetilde{A}} \times v_{B}\right\rangle \mid x \in X\right\} \\
& \lambda \times \widetilde{A}=\left\{\left\langle x, 1-\left(1-\mu_{\widetilde{A}}(x)\right)^{\lambda},\left(v_{\widetilde{A}}\right)^{\lambda}\right\rangle \mid x \in X\right\}
\end{aligned}
$$

The judgments of DMs-in the form of IFS-thus become the inputs for the final part of the hybrid model. The required steps in this part are as follows:

- Step 6: Request DMs to indicate their judgments regarding the belongingness and non-belongingness of an alternative on the antecedents (requirements) of a new criterion.

- Step 7: Synthesize the IFS performance scores of an alternative on each new criterion, and the IFS performance scores on all new criteria are to be synthesized at the last stage.

\section{Empirical Case and Ranking Experiments}

To be competitive in the semiconductor industry, IC design companies have to keep on launching $R \& D$ projects to enable attractive features or functions for new products. Although time-to-market is the key to success, certain innovative techniques with high potentials require a longer time to develop. With limited resources (e.g., budgets and engineers) on R\&D, IC design companies often have to select or prioritize a group of $R \& D$ projects to ensure their financial sustainability. This difficult yet valuable decision has to consider both the short- and long-term prospects under uncertainty; therefore, the case of supporting an IC design company on selecting new R\&D projects-using the hybrid decision model with the IFS evaluation technique-is illustrated as an empirical case.

\subsection{Data}

The hybrid decision model comprises two sources of inputs: (1) historical financial data of IC design companies; and (2) subjective judgments from DMs. On the one hand, all the public-listed IC companies' annual financial data in Taiwan, from 2008 to 2015, were adopted to form the bipolar decision model. In here, the FP changes in one and three years denote the short- and long-term financial changes, respectively; three sets of data, comprised of the conditional and decision attributes, were organized for each timeframe, which is illustrated in Figure 2. 

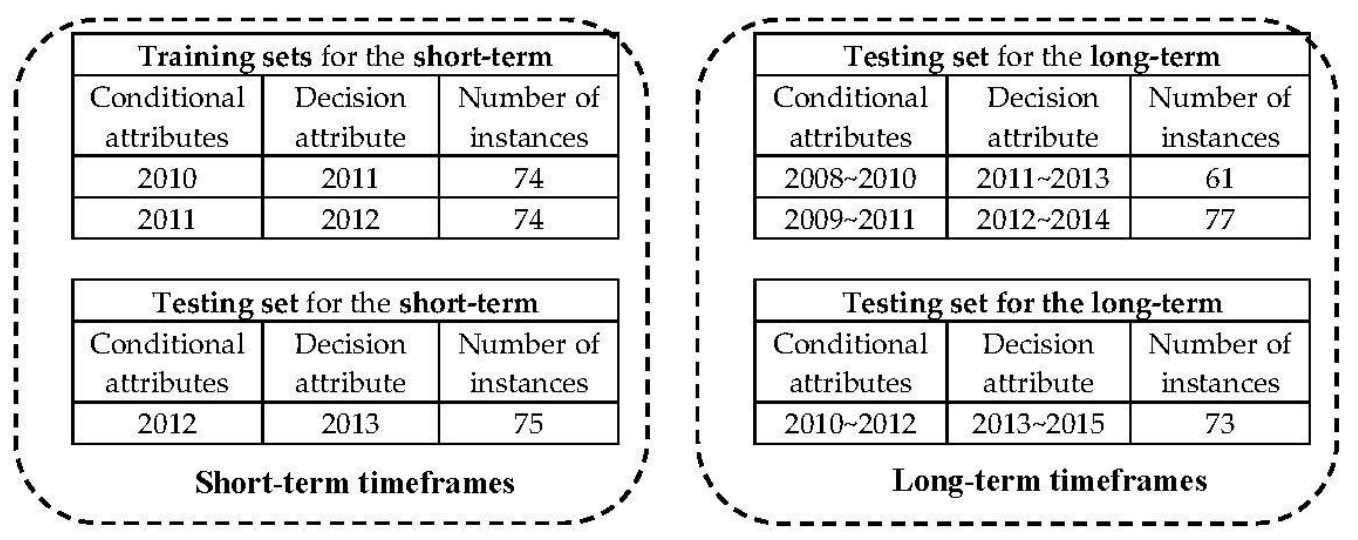

Figure 2. Timeframe illustration for the short- and long-term sub-models in DRSA.

All the financial data of the IC design stocks were retrieved from the TEJ [29] database. On the other hand, seven DMs from the same IC design company (named as NM in this study) were invited to provide their professional judgments (based on their experience and knowledge); three of the DMs work in the R\&D department, and the other four work in the Product Management department. They all possess more than 10 years of working experience in the IC design industry. The IC design company NM is not a public-listed company, which has three major product lines: audio, USB controller, and wireless related chipsets. Three R\&D projects (proposals) were evaluated by the seven DMs by using the inducted hybrid bipolar decision model with improvement analysis.

\subsection{Forming the Hybrid Bipolar Decision Model}

To form a hybrid bipolar decision model (based on historical changes in FP), the first step requires to defining the conditional and decision attributes—using DRSA algorithm—to form "if . . , then ... " decision rules. All the key financial ratios that the Taiwan Stock Exchange (TSE) releases regularly on its official website [30] were adopted in this study; 17 financial ratios of an IC design company at time period $t$ (as the conditional attributes) were associated with its relative ROE (return on equity, as the decision attribute) performance at time period $t+1$. The symbols and brief definitions of the used attributes are shown in Table 1.

To capture the imprecise logic of FP changes in both short- and long-term, two DRSA sub-models were formed. The associated periods of the training sets (learned instances) and the testing sets for the short- and long-term models are illustrated in Figure 2. After excluding incomplete data, there are 148 $(74+74)$ and $138(61+77)$ instances in the training sets of the short- and long-term models, respectively. The two training sets were analyzed by DRSA algorithm, as explained in Section 2.1. The DRSA models attempt to capture the imprecise patterns of FP changes based on fundamental analysis [22,23]; therefore, the raw financial data were transformed into the ordinal scale, to denote "Positive (POS)", "Neutral $(N E U)$ ", or "Negative (NEG)" by comparing an instance's raw figure, on the decision attribute (i.e., $R O E$ ), with the whole IC design industry at the same period. The top $1 / 3$ and the bottom $1 / 3$ were set as "POS" and "NEG", and the rest "NEU". The raw financial ratios of the conditional attributes were also transformed into the ordinal scale as "High $(H)$ ", "Mediocre $(M)$ ", and "Low $(L)$ " by the similar approach. All the instances' raw financial ratios of each conditional attribute at the same period (e.g., 2012) were ranked from high to low; the top $1 / 3$, the middle $1 / 3$, and the bottom $1 / 3$ were transformed into " $H$ ", " $M$ ", and " $L$ " respectively. This transformation enables a company to compare its relative performance on an attribute with the whole industry during the same period. 
Table 1. Summary of the conditional and decision attributes in DRSA.

\begin{tabular}{|c|c|c|}
\hline Conditional Attributes $^{1}$ & Symbol & Definition \\
\hline Debt to total asset & Debt & Totaldebt/Totalasset \\
\hline Long-term capital to total asset & LongCap & Long - termcapital/Totalasset \\
\hline Liquidity ratio & Liquidity & Currentasset/Currentliability \\
\hline Quick ratio & Quick & (Currentasset - Inventory)/Currentliability \\
\hline Accounts receivable ratio & ARturn & Netcreditsales/AveragedAR \\
\hline Days for collecting AR & ARdays & $($ Days $\times \mathrm{AR}) /$ Creditsales \\
\hline Inventory turnover rate & Inventory & Totaloperationalcost/Averageinventory \\
\hline Average days for sales & SaleDay & (Averageendinginventory/Operationalcost) $\times 365$ \\
\hline Fixed asset turnover & Fasset_turn & Total revenue/Total fixed asset \\
\hline Total asset turnover & Tasset_turn & Totalrevenue/Averagetotalasset \\
\hline Return on total asset & $R O A$ & Netprofitbeforetax/Averagetotalasset \\
\hline Net profit to total capital & NetP_to_cap & Netprofitbeforetax/Totalcapital \\
\hline Net profit ratio & NetP & Netprofit/Netsales \\
\hline Earnings per share & EPS & (Netincome - Dividendsonpreferredstocks) \\
\hline Earnings per share & EPS & $\begin{array}{c}\text { Totaloutstandingshares } \\
\text { (Netincome - Dividendsonpreferredstocks) }\end{array}$ \\
\hline Cash-flow & $C F$ & $\begin{array}{l}\text { Weightedaverageequity } \\
\end{array}$ \\
\hline Cash-flow adequacy & CF_adq & Cashflowfromoperation/Annualcurrentmaturities \\
\hline Cash-flow Reinvestment & CF_reinv & $\frac{(\text { Increasedfixedasset }+ \text { Increasedworkingcapital })}{(\text { Netincome }+ \text { noncashexpense }- \text { noncashsales }- \text { dividends })}$ \\
\hline Decision Attribute $^{1}$ & Symbol & Definition \\
\hline Return on equity & ROE & Netprofitbeforetax/Averagetotalequity \\
\hline
\end{tabular}

The accurateness of the models is measured by the rate of classification accuracy (CA), defined as the correctly classified instances divided by the whole group of instances. Both models were examined by a five-fold cross-validation for five times. In addition, two untouched testing sets (refer to Figure 2) were further validated. The averaged CAs of the short- and long-term models are $77.41 \%$ and $73.14 \%$, shown in Table 2, and the two testing sets also yield $75.34 \%$ and $69.33 \%$ CAs by adopting the trained models; this result has indicated certain degree of consistent financial patterns from the historical data, regarded as acceptable to form the subsequent bipolar decision models in this study. In the next, by setting the threshold as $80 \%$ (i.e., $\Omega=80 \%$ ) for the two timeframes, the covered positive and negative rules in the short- and long-term sub-models are reported in Tables 3 and 4 respectively.

Here additional explanations regarding how to identify those positive and negative rules in Tables 3 and 4 might be required. For instance, in the training set of the short-term sub-model, there were 50 instances categorized as "POS" before the rule-induction. Therefore, to cover $80 \%$ of "POS" instances, 40 "POS" instances $(50 \times 80 \%=40)$ should be covered by the minimal number of the strong positive rules—referring to Equation (11)—in the short-term model.

Table 2. Classification accuracy (CA) of the two sub-models (training sets).

\begin{tabular}{ccc}
\hline Experiments & Short-Term & Long-Term \\
\hline 1st & $75.38 \%{ }^{1}$ & $69.38 \%$ \\
2nd & $76.35 \%$ & $74.64 \%$ \\
3rd & $78.41 \%$ & $72.41 \%$ \\
4th & $79.13 \%$ & $74.82 \%$ \\
5th & $77.76 \%$ & $74.45 \%$ \\
Average & $77.41 \%$ & $73.14 \%$ \\
Standard Deviation & $1.53 \%$ & $2.32 \%$
\end{tabular}

${ }^{1}$ It denotes the CA of the short-term model using a five-fold validation at the first time. 
Table 3. Covered decision rules $(\Omega=80 \%)$ in the short-term sub-model.

\begin{tabular}{|c|c|c|c|}
\hline Rules ${ }^{1}$ & Antecedents (Requirements) & Consequence & Supp ${ }^{2}$ \\
\hline S_PR1 & $($ LongCap $\succeq M) \wedge($ SaleDay $\preceq L) \wedge($ Fasset_turn $\succeq H) \wedge(C F \succeq H)$ & $R O E \succeq P O S$ & 27 \\
\hline S_PR2 & 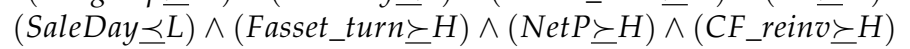 & $R O E \succeq P O S$ & 21 \\
\hline S_NR1 & $($ SaleDay $\succeq H) \wedge($ Tasset_turn $\preceq M) \wedge\left(C F \_r e i n v \preceq L\right)$ & $R O E \preceq N E G$ & 24 \\
\hline S_NR2 & $($ ARturn $\preceq M) \wedge($ Inventory $\preceq M) \wedge($ Fasset_turn $\preceq L) \wedge($ Net $P \preceq L)$ & $R O E \preceq N E G$ & 18 \\
\hline
\end{tabular}

Table 4. Covered decision rules $(\Omega=80 \%)$ in the long-term sub-model.

\begin{tabular}{|c|c|c|c|}
\hline Rules ${ }^{1}$ & Antecedents (Requirements) & Consequence & Supp ${ }^{2}$ \\
\hline L_PR1 & $($ Tasset_turn $\succeq H) \wedge(R O A \succeq H) \wedge\left(C F \_r e i n v \succeq H\right)$ & $R O E \succeq P O S$ & 20 \\
\hline L_PR2 & 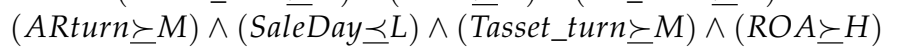 & $R O E \succeq P O S$ & 18 \\
\hline L_NR1 & $($ SaleDay $\succeq H) \wedge($ Tasset_turn $\preceq L) \wedge(R O A \preceq L)$ & $R O E \preceq N E G$ & 22 \\
\hline L_NR2 & $(Q$ uick $\preceq L) \wedge($ Inventory $\preceq M) \wedge($ Tasset_turn $\preceq M)$ & $R O E \preceq N E G$ & 14 \\
\hline
\end{tabular}

The original number of instances, the raw and normalized support weights of each rule, all summarized in Table 5 (refer to Equations (11)-(14)). One thing needs to be noticed in here: since several instances were covered by multiple rules, the sum of supports for positive or negative rules in each timeframe often exceeds the number of total instances screened out by the threshold. For example, the sum of supports of the positive rules in the short-term model exceeds 40 (i.e., $27+21>40$ ).

Table 5. Support weights of the two-timeframe (short and long) models.

\begin{tabular}{|c|c|c|c|c|c|c|c|c|}
\hline \multirow{3}{*}{$\begin{array}{l}\text { (Original/After_ } \Omega \text { ) } \\
\text { Decision rule }\end{array}$} & \multicolumn{4}{|c|}{ Short-Term } & \multicolumn{4}{|c|}{ Long-Term } \\
\hline & \multicolumn{2}{|c|}{ POS $(50 / 40)$} & \multicolumn{2}{|c|}{ NEG $(48 / 38)$} & \multicolumn{2}{|c|}{ POS $(43 / 34)$} & \multicolumn{2}{|c|}{ NEG (40/32) } \\
\hline & S PR1 & S PR2 & S NR1 & S NR2 & L PR1 & L PR2 & L NR1 & L NR2 \\
\hline Supports & 27 & 21 & 24 & 18 & 20 & 18 & 22 & 14 \\
\hline Support weights & $67.50 \%{ }^{1}$ & $52.50 \%$ & $63.16 \%$ & $47.37 \%$ & $52.63 \%$ & $47.27 \%$ & $61.11 \%$ & $38.89 \%$ \\
\hline N.S.weights & $28.13 \%{ }^{2}$ & $21.88 \%$ & $28.57 \%$ & $21.43 \%$ & $26.32 \%$ & $23.63 \%$ & $30.56 \%$ & $19.44 \%$ \\
\hline
\end{tabular}

\footnotetext{
${ }^{1}$ Support weight is calculated by Support/After_ $\Omega$ (e.g., $\left.27 / 40=67.50 \%\right) ;{ }^{2}$ N.S.weight denotes the normalized support weight, and the sum of normalized support weights in each sub-model (short or long-term) should be $100.00 \%$.
}

\subsection{Ranking of Four Example Companies with Consistency Check}

After finding the normalized support weight for each decision rule of the two sub-models, four public-listed IC design companies from Taiwan were examined by using their recent data. The four companies are: $(A)$ Silicon Integrated Systems (code: 2363); (B) VIA tech (code: 2388); (C) Novatech (code: 3034); and (D) Advanced Power Electronics (code: 8261). The four companies' financial records on the conditional attributes in 2012 were transformed into the ordinal scale, as described in Section 3.2, taken as the inputs for their short-term models; similarly, their averaged financial records on the conditional attributes, from 2010 to 2012, were adopted as the inputs for the long-term ones.

For each rule, the performance score ranges from 0.00 to 1.00, and the score of a company on a positive rule depends on the satisfied percentage of antecedents (requirements) on it. For instance, if company $X$ met three of the four antecedents of rule S_PR2, its performance score would be $75 \%(3 / 4=75 \%)$ in this positive rule. As for those negative rules, the score is determined by the unsatisfied percentage of antecedents (requirements) of a rule, which indicates its dissimilarity with the negative ones. For instance, if one of the three antecedents of company $X$ was not satisfied on S_NR1, its performance score would then be $33.33 \%$ for this rule. 
To examine the effectiveness of the hybrid model, the simple additive weighting (SAW) method was adopted at first, and different weights of expectation were put on the two timeframes to examine its consistency. The performance scores of the four company on each rule are shown in Table 6, and the aggregated final performance scores of the four companies are reported in Table 7, under different weights of expectation. Take company $A$ as an example; while 100\% expectation (emphasis) of financial prospect was put on the short-term (i.e., Short-Term:Long-Term = 1.0:0.0 in Table 7), the final score of company $A$ would be 28.52 .

Table 6. Transformed performance scores of the four companies on the decision rules.

\begin{tabular}{ccccccccc}
\hline Timeframes & \multicolumn{3}{c}{ Short-Term } & \multicolumn{3}{c}{ Long-Term } \\
\hline & \multicolumn{2}{c}{ POS } & \multicolumn{2}{c}{ NEG } & \multicolumn{2}{c}{ POS } & \multicolumn{2}{c}{ NEG } \\
\hline Companies & S_PR1 & S_PR2 & S_NR1 & S_NR2 & L_PR1 & L_PR2 & L_NR1 & L_NR2 \\
\hline$A$ & $62.50 \%$ & $50.00 \%$ & $0.00 \%$ & $0.00 \%$ & $50.00 \%$ & $62.50 \%$ & $16.67 \%$ & $16.67 \%$ \\
$B$ & $50.00 \%$ & $50.00 \%$ & $0.00 \%$ & $12.50 \%$ & $50.00 \%$ & $62.50 \%$ & $0.00 \%$ & $0.00 \%$ \\
C & $87.50 \%$ & $87.50 \%$ & $33.33 \%$ & $37.50 \%$ & $66.67 \%$ & $75.00 \%$ & $50.00 \%$ & $33.33 \%$ \\
$D$ & $62.50 \%$ & $50.00 \%$ & $16.67 \%$ & $100.00 \%$ & $83.33 \%$ & $62.50 \%$ & $16.67 \%$ & $16.67 \%$ \\
\hline
\end{tabular}

Table 7. Aggregated final scores of the four companies under different expectation (by SAW).

\begin{tabular}{cccccccc}
\hline \multicolumn{7}{c}{ Weights of Expectation (Short-Term:Long-Term) } \\
\hline Companies & $\mathbf{( 1 . 0 : 0 . 0 )}$ & $\mathbf{( 0 . 8 : 0 . 2 )}$ & $\mathbf{( 0 . 6 : 0 . 4 )}$ & $\mathbf{( 0 . 5 : 0 . 5 )}$ & $\mathbf{( 0 . 4 : 0 . 6 )}$ & $\mathbf{( 0 . 2 : 0 . 8 )}$ & $\mathbf{( 0 . 0 : 1 . 0 )}$ \\
\hline$A$ & $28.52^{1}$ & 30.07 & 31.61 & 32.39 & 33.16 & 34.71 & 36.26 \\
$B$ & 27.68 & 27.73 & 27.78 & 27.80 & 27.83 & 27.88 & 27.93 \\
$C$ & 61.31 & 60.45 & 59.60 & 59.17 & 58.74 & 57.89 & 57.03 \\
$D$ & 54.71 & 52.77 & 50.84 & 49.87 & 48.90 & 46.97 & 45.04 \\
\hline
\end{tabular}

1 The final score of $A$ was calculated by putting $100 \%$ weighting on the short-term expectation: $f_{A}=$ $\left\{1.0 \times\left[\left(\sum_{i=1}^{2} S_{w i} w_{i}^{P O S} \times{ }^{S} f_{i A}^{P O S}\right)+\left(\sum_{j=1}^{2} S w_{j}^{N E G} \times{ }^{S} f_{j A}^{N E G}\right)\right]+0.0 \times\left[\left(\sum_{i=1}^{2}{ }^{L} w_{i}^{P O S} \times{ }^{L} f_{i A}^{P O S}\right)+\left(\sum_{j=1}^{2}{ }^{L} w_{j}^{N E G} \times{ }^{L} f_{j A}^{N E G}\right)\right]\right\} \times$ 100 , where ${ }^{S} w_{i}^{P O S}$ denotes the normalized support weight of the $i$-th positive rule in the short-term model and ${ }^{S} f_{i A}^{P O S}$ represents the associated performance score of company $A$ on this rule; the other symbols follow the similar logic.

From Table 7, by setting different weights on the short- and long-term sub-models, all suggested that the ranking would be: $C \succ D \succ A \succ B$. The actual financial results of the four companies during 2013 to 2015 (i.e., their ROEs in 2013 denotes the short-term results and the averaged ROE from 2013 to 2015 the long-term ones) are shown in Table 8.

Table 8. Actual/averaged ROEs of the four companies in different timeframes (Unit: \%).

\begin{tabular}{ccccc}
\hline & $\mathbf{2 0 1 3}$ & $\mathbf{2 0 1 4}$ & $\mathbf{2 0 1 5}$ & $\mathbf{2 0 1 3 - 2 0 1 5} \mathbf{1 3}^{\mathbf{1}}$ \\
\hline$A$ & -3.90 & -1.48 & 0.14 & -1.75 \\
$B$ & -37.36 & -86.65 & 30.47 & -31.18 \\
$C$ & 19.27 & 25.54 & 22.44 & 22.42 \\
$D$ & -5.59 & 7.56 & 7.13 & 3.03 \\
\hline \multicolumn{4}{l}{${ }^{1}$ It denotes the averaged ROE, from 2013 to 2015 (i.e., long-term). }
\end{tabular}

After examining the combinations of different weights of expectation on the four companies' short(2013) and long-term (from 2013 to 2015) prospects, most of the rankings in Table 9 were consistent with the hybrid model's results in Table 7 (i.e., $C \succ D \succ A \succ B$ ). However, although the top-ranked one was still company $C$, the ranking turned out to be $C \succ A \succ D \succ B$ while putting more weight on the short-term (i.e., $\geq 80 \%$ weight on the short-term). 
Table 9. Actual ROE-combinations of the four companies under different expectation (Unit: \%).

\begin{tabular}{cccccccc}
\hline \multicolumn{7}{c}{ Weights of Expectation (Short-Term (2013):Long-Term (2013-2015)) } \\
\hline c-ROE $^{\mathbf{1}}$ (Rank) & $\mathbf{( 1 . 0 : 0 . 0 )}$ & $\mathbf{( 0 . 8 : 0 . 2 )}$ & $\mathbf{( 0 . 6 : 0 . 4 )}$ & $\mathbf{( 0 . 5 : 0 . 5 )}$ & $\mathbf{( 0 . 4 : 0 . 6 )}$ & $\mathbf{( 0 . 2 : 0 . 8 )}$ & $\mathbf{( 0 . 0 : 1 . 0 )}$ \\
\hline$A$ & $-3.90(2)$ & $-3.47(2)$ & $-3.04(3)$ & $-2.83(3)$ & $-2.61(3)$ & $-2.18(3)$ & $-1.75(3)$ \\
$B$ & $-37.36(4)$ & $-36.13(4)$ & $-34.89(4)$ & $-34.27(4)$ & $-33.65(4)$ & $-32.42(4)$ & $-31.18(4)$ \\
$C$ & $19.27(1)$ & $19.90(1)$ & $20.53(1)$ & $20.85(1)$ & $21.16(1)$ & $21.79(1)$ & $22.42(1)$ \\
$D$ & $-5.59(3)$ & $-3.87(3)$ & $-2.14(2)$ & $-1.28(2)$ & $-0.42(2)$ & $1.31(2)$ & $3.03(2)$ \\
\hline
\end{tabular}

${ }^{1} \mathrm{c}$-ROE denotes the combined ROE in different weights of expectation of the short- and long-term. For instance, while putting $80 \%$ weight on the short-term and $20 \%$ the long-term (i.e., (0.8:0.2) in this table), c-ROE of company $A$ was calculated as: $-3.47 \%=0.8 \times(-3.90 \%)+0.2 \times(-1.75 \%)$.

Furthermore, this study undertook the other aggregation method, the modified-VIKOR (explained in Appendix A), to compare the ranking result as an additional consistency check. Unlike the SAW method, the modified-VIKOR collects the weighted performance gap on each rule (criterion), and it aims to select the alternative with the minimal aggregated performance gap. The ranking results are the same (while setting $v=50 \%$ ) as using the SAW method in Table 7, which suggests the effectiveness of the hybrid model. The detail calculations of the modified VIKOR method are in Appendix A.

\section{Discussions on Selecting New R\&D Projects and Improvement Planning}

After showing the effectiveness of the hybrid decision model on ranking, a case of selecting R\&D projects for the NM company was analyzed by applying this hybrid model. The assessment of new $R \& D$ projects depends on the experience and knowledge of experts (DMs); however, owing to the uncertainty and limited information of new projects at the infant stage, the IFS technique was adopted to reserve the degree of hesitancy of DMs, during the evaluations.

Three projects were assessed for all the requirements (e.g., "SaleDay $\preceq L "$ in L_PR2) of the short- and long-term sub-models by the aforementioned seven DMs. The degrees of satisfaction and dissatisfaction of the three projects, on each requirement, were graded by the seven DMs, shown in Appendix B, and the averaged figures were used for the evaluations. To calculate the scores of the three projects on each rule, the IFS operator for weighted averaging (OWA) [31] and an IFS-based score function $M(A)$ [32] were adopted, defined in Equations (19)-(21), respectively. Assume that $A_{j}=\left\langle\mu_{j}, \omega_{j}\right\rangle$ for $j=1,2, \ldots, n$, which are intuitionistic fuzzy sets and $\hat{A}_{k}=\left\langle\hat{\mu}_{k}, \hat{\omega}_{k}\right\rangle$ denotes the $k$-th largest IFS of the set $A$.

$$
\begin{gathered}
g_{j}^{A}\left(A_{1}, \ldots, A_{n}\right)=\left(1-\prod_{k=1}^{n}\left(1-\hat{\mu}_{k}\right)^{w_{k}}, \prod_{k=1}^{n} \hat{\omega}_{k}^{w_{k}}\right) \\
g_{w}^{O W A}\left(A_{1}, \ldots, A_{n}\right)=\sum_{k=1}^{n} w_{k} \hat{A}_{k}
\end{gathered}
$$

where $w_{k}$ is the $k$-th largest weight of $A$, which also appears in the ensuing function $M$. The IFS-based score function $M$ is proposed for ranking decision in the context of MCDM, defined in Equation (22). The value of $M(A)$ ranges from -1 to 1 , and $\mu+\omega$ indicates the accuracy of the IFS $A$.

$$
M(A)=\mu-\omega
$$

To form the IFS-based hybrid decision model, the three projects' scores (degrees of satisfaction and dissatisfaction) on each rule need to be calculated. In here, all the requirements of a rule (both the positive and negative rules) were assumed to be equally important. Take the rule L_PR1 for instance, the three requirements (i.e., Tasset_tur $\succeq$ $\succeq, R O A \succeq H$, andCF_reinv $\succeq H$ ) were assumed to be equally weighted as $33.33 \%$. As a result, using the IFS-based OWA (refer to Equations (20) and (21)) for each rule, the IFS-based evaluation results of the three projects were obtained, which are reported in 
Table 10. In the next, the three projects' score-values of $\left(\mu_{j}, \omega_{j}\right)$ were transformed into $M\left(A_{j}\right)$, and the normalized support weight of each rule (from Table 5 ) were adopted to form the final evaluations, as reported in Table 11.

Table 10. IFS-based assessments of the three projects on the decision rules.

\begin{tabular}{ccccccccc}
\hline \multirow{2}{*}{ Timeframes } & \multicolumn{4}{c}{ Short-Term } & \multicolumn{3}{c}{ Long-Term } \\
\cline { 2 - 9 } & \multicolumn{2}{c}{ POS } & \multicolumn{2}{c}{ NEG } & \multicolumn{2}{c}{ POS } & NEG \\
\hline Rules & S_PR1 & S_PR2 & S_NR1 & S_NR2 & L_PR1 & L_PR2 & L_NR1 & L_NR2 \\
\hline Project 1 & $(0.70,0.16)$ & $(0.67,0.17)$ & $(0.59,0.22)$ & $(0.67,0.29)$ & $(0.56,0.30)^{1}$ & $(0.73,0.20)$ & $(0.62,0.21)$ & $(0.62,0.31)$ \\
Project 2 & $(0.50,0.15)$ & $(0.50,0.16)$ & $(0.51,0.21)$ & $(0.57,0.27$ & $(0.47,0.26)$ & $(0.58,0.20)$ & $(0.53,0.24)$ & $(0.56,0.34)$ \\
Project 3 & $(0.42,0.17)$ & $(0.45,0.18)$ & $(0.38,0.23)$ & $(0.50,0.33)$ & $(0.39,0.39)$ & $(0.55,0.26)$ & $(0.54,0.21)$ & $(0.52,0.30)$ \\
\hline
\end{tabular}

${ }^{1}$ The IFS-based assessments of the three projects on each rule were calculated by using IFS OWA; $\mu_{1}^{\mathrm{L}_{1} \mathrm{PR} 1}=1-$ $(1-0.76)^{1 / 3} \times(1-0.53)^{1 / 3} \times(1-0.29)^{1 / 3}=0.56$ and $\omega_{1}^{L_{-} \text {PR1 }}=(1-0.21)^{1 / 3} \times(1-0.44)^{1 / 3} \times(1-0.28)^{1 / 3}=$ 0.30 , where the averaged degree of satisfaction and dissatisfaction of the three projects, on each requirement, can be found in Appendix B.

Table 11. $M(A)$ values and the final scores (ranking) of the three projects by SAW method (while equally weighted on the short- and long-term prospects).

\begin{tabular}{cccccccccc}
\hline \multirow{2}{*}{ Timeframes } & \multicolumn{4}{c}{ Short-Term } & \multicolumn{7}{c}{ Long-Term } \\
\cline { 2 - 11 } POS & \multicolumn{3}{c}{ NEG } & \multicolumn{3}{c}{ POS } & \multicolumn{3}{c}{ NEG } \\
\hline Rules & S_PR1 & S_PR2 & S_NR1 & S_NR2 & L_PR1 & L_PR2 & L_NR1 & L_NR2 & Scores \\
\hline N.S.Weight & $28.13 \%$ & $21.88 \%$ & $28.57 \%$ & $21.43 \%$ & $26.32 \%$ & $23.63 \%$ & $30.56 \%$ & $19.44 \%$ & (Ranking) \\
\hline Project 1 & 0.54 & 0.50 & 0.37 & 0.38 & 0.26 & 0.53 & 0.41 & 0.30 & $41.42(1){ }^{1}$ \\
Project 2 & 0.35 & 0.34 & 0.30 & 0.29 & 0.21 & 0.38 & 0.28 & 0.23 & $29.91(2)$ \\
Project 3 & 0.26 & 0.27 & 0.15 & 0.17 & 0.00 & 0.29 & 0.33 & 0.22 & $21.13(3)$ \\
\hline
\end{tabular}

${ }^{1}$ The final score of project 1 , while equally weighted on the short- and long-term prospect, calculated as: $41.42=\left[\begin{array}{c}0.5 \times(0.54 \times 28.13 \%+0.50 \times 21.88 \%+0.37 \times 28.57 \%+0.38 \times 21.43 \%) \\ +0.5 \times(0.26 \times 26.32 \%+0.53 \times 23.63 \%+0.41 \times 30.56 \%+0.30 \times 19.44 \%)\end{array}\right] \times 100$.

In Table 11, it can be observed that Project 1 should be selected if the NM company equally weights its expectation on the short- and long-term financial prospects. Although uncertainty remains, the ranking result has been based on the analytics integrated from the machine-learning (i.e., the hybrid decision model formed in Section 3) and the IFS-based judgments of DMs, which provides transparent decision aids on selecting R\&D projects. This is the main contribution and novelty of the proposed approach.

In addition, once a new R\&D project is selected, the company can identify the project's weighted weakness, in terms of the plausible financial consequences, to strengthen its competitiveness. Usually, at the early stage of a $R \& D$ project, $R \& D$ managers need to set up the development direction (strategy) of a project based on their own judgments or customer feedbacks. Although R\&D managers would have specific technical concerns, the ultimate goal of R\&D projects is still generating financial returns, no matter in the short- or long-term. This hybrid model can provide additional information to support this complicated decision. Use Project 1 as an example, Table 12 highlights its top-three improvement priority of the hybrid model under different weighting on the short- and long-term prospects.

From Table 12, it can be observed that if the NM company puts more weight on the short-term (i.e., $80 \%$ on the short-term prospect), the top priority (underperformed criterion) of Project 1 would be on the rule L_NR1 (i.e., negative rule \#1 of the long-term model). On the other hand, while the shortand long-term prospects are equally weighted, or much more expectation is placed on the long-term (e.g., $80 \%$ on the long-term in Table 12), the top priority would be shifted to S_PR1. Referring Table 4,

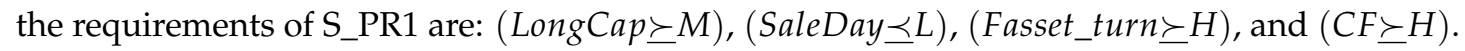


Table 12. Top three improvement priority of Project 1 under different expectation.

\begin{tabular}{ccccccccc}
\hline Timeframes & \multicolumn{3}{c}{ Short-Term } & \multicolumn{3}{c}{ Long-Term } \\
\hline & \multicolumn{2}{c}{ POS } & \multicolumn{2}{c}{ NEG } & \multicolumn{2}{c}{ POS } & NEG \\
\hline Rules & S_PR1 & S_PR2 & S_NR1 & S_NR2 & L_PR1 & L_PR2 & L_NR1 & L_NR2 \\
\hline N.S.Weight & $28.13 \%$ & $21.88 \%$ & $28.57 \%$ & $21.43 \%$ & $26.32 \%$ & $23.63 \%$ & $30.56 \%$ & $19.44 \%$ \\
(Short:Long = 0.8:0.2) & $3.03 \%{ }^{1}$ & $2.19 \%$ & $2.09 \%$ & $1.62 \%$ & $5.57 \%$ & $10.08 \%$ & $10.11 \%$ & $4.69 \%$ \\
Top 3 priority & & & & & $3 \mathrm{rd}$ & $2 \mathrm{nd}$ & $1 \mathrm{st}$ & \\
(Short:Long = 0.5:0.5) & $7.57 \%$ & $5.47 \%$ & $5.22 \%$ & $4.05 \%$ & $3.48 \%$ & $6.30 \%$ & $6.32 \%$ & $2.93 \%$ \\
Top 3 priority & $1 \mathrm{st}$ & & & & & $3 \mathrm{rd}$ & $2 \mathrm{nd}$ & \\
(Short:Long = 0.2:0.8) & $12.12 \%$ & $8.74 \%$ & $8.35 \%$ & $6.48 \%$ & $1.39 \%$ & $2.52 \%$ & $2.53 \%$ & $1.17 \%$ \\
Top 3 priority & $1 \mathrm{st}$ & 2nd & 3rd & & & & & \\
\hline 1
\end{tabular}

${ }^{1}$ It denotes the weighted performance score of Project 1 while $80 \%$ and $20 \%$ expectation are placed on the shortand long-term, which is calculated as: $3.03 \%=28.13 \% \times 0.8 \times 0.54$.

In other words, the R\&D managers can learn from the analytics that the development direction (strategy) of Project 1 should focus on being more "similar with the four requirements in S_PR1" to achieve superior short-term financial prospect. Take the requirement " $(C F \succeq H)$ " and "(SaleDay $\preceq L)$ " for example, R\&D managers may consider how to increase the cash flows and shorten the average days for sales of those plausible products, extended from Project 1 . Those analytics can thus provide understandable guidance for R\&D managers to improve the selected new projects, compromised between the short- and long-term financial prospects, to be in line with the company's financial policy.

\section{Concluding Remarks}

In sum, the present work is a preliminary study on supporting R\&D decisions while a company needs to compromise between the short- and long-term financial sustainability. Based on literature review [1-9] and the discussions with experts (DMs), this study presumes the existence of short-termism, which might influence managers on making crucial business decisions. Furthermore, unlike the previous research that merely highlighted the existence of short-termism, this work proposes a hybrid model to support this kind of complicated decisions in business operations, and a case of selecting new R\&D projects is illustrated as a numerical example.

To learn the complex if-then logics of financial changes, the historical reports of public-listed IC design companies from Taiwan were inducted to form a hybrid bipolar decision model. Using DRSA as the core algorithm, the learned bipolar model comprises the short- and long-term sub-models, to support ranking (selection) decisions. Although minor inconsistency exists, the hybrid model has shown its effectiveness on ranking four IC design companies in Section 3. It is worthwhile to notice that the hybrid model conveys understandable insights that may lead to financial returns in different timeframes.

In Section 4, the inducted bipolar model further integrates with the subjective judgments from the DMs, using the IFS technique, to evaluate new R\&D projects. Although the examined company has its constraints and financial structure, the inducted knowledge (in the form of decision rules) from the same industry should be a good source for the company to learn or reference. As a result, the present study presumes that the future changes in financial patterns of the case company could be similar to those public-listed IC design companies' historical patterns, which is the limitation of this research.

The integrated hybrid decision model not only supports to select Project 1 from the three projects, it also identified the priority for Project 1 to improve, which could guide R\&D managers to adjust the development direction (strategy) of this project. In Table 12, it shows that the top priority is not always the same. If the NM company's policy inclines to the short-term financial prospect (e.g., $80 \%$ weight in short-term), its top priority would be L_NR1; on the other side, while more emphasis is placed on the long-term, the top priority turns out to be S_PR1. This finding implies that the policy of a company (toward the short- and long-term financial prospect) should be comprehended by managers, to make 
congruent R\&D decisions. The present study has proposed a hybrid decision model, integrating the inputs from machine learning and judgments from DMs, to meet this end.

Although the present study has yielded findings that have both theoretical and practical implications, some other limitations remain. First, the learned hybrid bipolar model is based on the assumption: the similar financial patterns will recur in the near future. Second, some requirements of a rule could not be directly affected by R\&D decisions or activities. Examples are the capital structure and cash flow reinvestment ratios; those requirements are mainly influenced by financial decisions, rather than the R\&D ones. Third, the hybrid bipolar model presumes that all the requirements in a rule are equally important; this assumption could be relaxed by using some other MCDM or soft computing methods in the future. Fourth, this study adopts the additive type aggregators (i.e., SAW and modified VIKOR); some other non-additive type aggregators (e.g., fuzzy integral [33]) may be applied to measure the plausible synergy effects among criteria. Last, this approach is only applicable for those R\&D projects that can be associated with marketable products; projects that could not yield foreseeable products are not suitable to be evaluated by this model.

In spite of all the assumptions and limitations of the present study, it has contributed to devising a practical model on selecting and guiding R\&D projects. In the era of big-data, DMs have opportunities to make informed prudent decisions based on the findings learned from imprecise and uncertain data sets [34]. How to leverage the advantages of machine learning and preserve the professional judgments of DMs is a challenging and valuable research topic; it is hoped that this hybrid model can serve as a basis for further research in this direction.

Acknowledgments: This work is funded by the Ministry of Science and Technology (MOST) of Taiwan (R.O.C.) under the grant number MOST-105-2410-H-034-019-MY2. The author sincerely appreciates the financial sponsor. In addition, the feedback and valuable opinions of the managers of the NM company have enriched the findings of this study in many aspects.

Conflicts of Interest: The author declares no conflict of interest.

\section{Appendix A. Calculations of the Modified VIKOR Method on Ranking}

One of the $L_{p}$-matrix-based aggregators, the modified VIKOR [35-37], is referenced and served to test the robustness of the hybrid bipolar model. The original idea of VIKOR is inspired by the works of Yu [38] and Zeleny [39], and it was modified by setting the aspired level as the benchmark for an alternative while calculating its performance score on a criterion. In the present study, the modified VIKOR method is adopted by setting $p=1$ in Equation (A1).

Assume that there are $S$ alternatives, the IFS performance score of the alternative $g$ on the $i$ th positive criterion and on the $j$ th negative criterion are denoted as $f_{\widetilde{g} i}$ and $f_{\widetilde{g} j}$, and $\underline{w}_{i}^{P O S}$ and $\underline{w}_{j}^{N E G}$ are the normalized support weights of the $i$ th positive and the $j$ th negative criteria. One thing needs to be noticed in here: the scores on the negative rules are determined by the unsatisfied percentage of antecedents. Thus, unlike the conventional VIKOR method [36,37], the corresponding $L_{p}$-matrix of this hybrid model is shown in Equation (A1):

$$
L_{P}=\left\{\left[\sum_{i=1}^{k}\left(\underline{w}_{i}^{P O S}\left(\left|f_{i}^{*}-f_{\widetilde{g} i}\right|\right) /\left(f_{i}^{*}-f_{i}^{-}\right)\right)+\sum_{j=1}^{l}\left(\underline{w}_{j}^{N E G}\left(\left|f_{j}^{*}-f_{\widetilde{g} j}\right|\right) /\left(f_{j}^{*}-f_{j}^{-}\right)\right)\right]^{p}\right\}^{\frac{1}{P}}
$$

where $1 \leq p \leq \infty, i=1, \ldots, k$ and $j=1, \ldots, l$.

In Equation (A1), $f_{i}^{*}$ and $f_{i}^{-}$are set as the aspired and the worst values on the $i$ th positive rule (criterion); similarly, $f_{j}^{*}$ and $f_{j}^{-}$are set as the aspired and the worst values on the $j$ th negative rule (criterion). The $S$-index can be obtained by setting $p=1$ in Equation (A1), which denotes the aggregated performance gap of the alternative $g$. In the addressed dual-timeframe problem, DMs should aggregate the performance scores from two sub-bipolar models based on their emphases on the short- and long-term prospects, respectively. 
In the modified VIKOR method, $\left|f_{i}^{*}-f_{\widetilde{g} i}\right| /\left(f_{i}^{*}-f_{i}^{-}\right)$or $\left|f_{j}^{*}-f_{\widetilde{g} j}\right| /\left(f_{j}^{*}-f_{j}^{-}\right)$is defined as $r_{t i}$ or $r_{t j}$ (for $t=1, \ldots, 4$ ); and $f^{*}$ and $f^{-}$are set to be $100 \%$ and $0 \%$, respectively. In each sub-model (i.e., the short- or long-term one), three indices, $S_{t}, R_{t}$ and $Q_{t}$, need to be obtained before forming the final performance scores, and the ranking result is based on the index $Q_{t}$.

$$
\begin{gathered}
S_{t}=\sum_{i=1}^{k} \underline{w}_{i}^{P O S} r_{t i}+\sum_{j=1}^{l} \underline{w}_{j}^{N E G} r_{t j} \\
R_{t}=\max \left\{\underline{w}_{i}^{P O S} \times r_{t i}, \underline{w}_{j}^{N E G} \times r_{t j} \mid i=1,2 ; j=1,2\right\} \\
Q_{t}=v \times S_{t}+(1-v) \times R_{t}
\end{gathered}
$$

where $k=l=2$ (in Equation (A2)) in both the short- and long-term sub-models. In this case, by setting $v=0.5$, the three indices of the four companies are reported in Table A1.

Table A1. Performance gaps and indices of the four companies (short-term).

\begin{tabular}{ccccccccc}
\hline Companies & N.S.Weight & S_PR1 & S_PR2 & S_NR1 & S_NR2 & $S_{t}^{S}$ & $R_{t}^{S}$ & $Q_{t}^{S}$ \\
\hline$A$ & $28.13 \%$ & $37.50 \%$ & $50.00 \%$ & $100.00 \%$ & $100.00 \%$ & $71.48 \%$ & $28.57 \%$ & $50.03 \%$ \\
$B$ & $21.88 \%$ & $50.00 \%$ & $50.00 \%$ & $100.00 \%$ & $87.50 \%$ & $72.32 \%$ & $28.57 \%$ & $50.45 \%$ \\
$C$ & $28.57 \%$ & $12.50 \%$ & $12.50 \%$ & $66.67 \%$ & $62.50 \%$ & $38.69 \%$ & $19.05 \%$ & $28.87 \%$ \\
$D$ & $21.43 \%$ & $37.50 \%$ & $50.00 \%$ & $83.33 \%$ & $0.00 \%$ & $45.29 \%$ & $23.81 \%$ & $34.55 \%$ \\
\hline
\end{tabular}

All the ranking results show $C \succ D \succ A \succ B$, which are consistent with the findings in Section 3 .

Table A2. Performance gaps and indices of the four companies (long-term).

\begin{tabular}{ccccccccc}
\hline Companies & N.S.weight & L_PR1 & L_PR2 & L_NR1 & L_NR2 & $S_{t}^{L}$ & $R_{t}^{L}$ & $Q_{t}^{L}$ \\
\hline$A$ & $26.32 \%$ & $50.00 \%$ & $37.50 \%$ & $83.33 \%$ & $83.33 \%$ & $63.69 \%$ & $25.46 \%$ & $44.57 \%$ \\
$B$ & $23.63 \%$ & $50.00 \%$ & $37.50 \%$ & $100.00 \%$ & $100.00 \%$ & $72.02 \%$ & $30.56 \%$ & $51.29 \%$ \\
$C$ & $30.56 \%$ & $33.33 \%$ & $25.00 \%$ & $50.00 \%$ & $66.67 \%$ & $42.92 \%$ & $15.28 \%$ & $29.10 \%$ \\
$D$ & $19.44 \%$ & $16.67 \%$ & $37.50 \%$ & $83.33 \%$ & $83.33 \%$ & $54.91 \%$ & $25.46 \%$ & $40.19 \%$ \\
\hline
\end{tabular}

${ }^{1}$ Refer Table 6, $50 \%$ denotes the performance gap of $A$ on L_PR1: $50 \%=(1-50 \%) /(100 \%-0)$.

Table A3. Aggregated scores of the four companies under different expectation (by VIKOR).

\begin{tabular}{cccccccc}
\hline \multicolumn{7}{c}{ Weights of Expectation (Short-Term:Long-Term) } \\
\hline Companies & $\mathbf{( 1 . 0 : 0 . 0 )}$ & $\mathbf{( 0 . 8 : 0 . 2 )}$ & $\mathbf{( 0 . 6 : 0 . 4 )}$ & $\mathbf{( 0 . 5 : 0 . 5 )}$ & $\mathbf{( 0 . 4 : 0 . 6 )}$ & $\mathbf{( 0 . 2 : 0 . 8 )}$ & $\mathbf{( 0 . 0 : 1 . 0 )}$ \\
\hline$A$ & $50.03 \%$ & $45.66 \%$ & $46.76 \%$ & $47.30 \%$ & $47.85 \%$ & $48.94 \%$ & $44.57 \%$ \\
$B$ & $50.45 \%$ & $51.12 \%$ & $50.95 \%$ & $50.87 \%$ & $50.78 \%$ & $50.61 \%$ & $51.29 \%$ \\
$C$ & $28.87 \%$ & $29.05 \%$ & $29.01 \%$ & $28.98 \%$ & $28.96 \%$ & $28.92 \%$ & $29.10 \%$ \\
$D$ & $34.55 \%$ & $39.06 \%$ & $37.93 \%$ & $37.37 \%$ & $36.81 \%$ & $35.68 \%$ & $40.19 \%$ \\
\hline \multicolumn{7}{c}{${ }^{1}$ It weights 80\% on $Q_{t}^{S}$ and $20 \%$ on $Q_{t}^{L}($ i.e., $45.66 \%=0.8 \times 50.03 \%+0.2 \times 44.57)}$.
\end{tabular}

\begin{tabular}{|c|c|c|c|c|}
\hline Rule Types & Requirements & Project 1 & Project 2 & Project 3 \\
\hline Long_Positive & Tasset_turn $\succeq H$ & $(0.76,0.21)^{1}$ & $(0.59,0.22)$ & $(0.34,0.47)$ \\
\hline Long_Positive & $R O A \succeq \bar{H}$ & $(0.53,0.44)$ & $(0.52,0.31)$ & $(0.51,0.43)$ \\
\hline Long_Positive & $C F \_$reinv $\succeq H$ & $(0.29,0.28)$ & $(0.25,0.24)$ & $(0.29,0.28)$ \\
\hline Long_Positive & $A R t u r n \succeq M$ & $(0.81,0.14)$ & $(0.59,0.17)$ & $(0.57,0.17)$ \\
\hline Long_Positive & 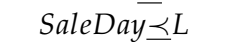 & $(0.76,0.20)$ & $(0.61,0.20)$ & $(0.70,0.20)$ \\
\hline Long_Positive & Tasset_turn $\succeq M$ & $(0.85,0.12)$ & $(0.62,0.16)$ & $(0.49,0.33)$ \\
\hline
\end{tabular}

\section{Appendix B. Averaged IFS Assessments of the Three Projects by the DMs}

Table A4. Averaged IFS assessment for the requirements of the three projects. 
Table A4. Cont.

\begin{tabular}{|c|c|c|c|c|}
\hline Rule Types & Requirements & Project 1 & Project 2 & Project 3 \\
\hline Long_Negative & SaleDay $\succeq H$ & $(0.60,0.21)$ & $(0.56,0.24)$ & $(0.54,0.22)$ \\
\hline Long_Negative & Tasset_turn $\preceq L$ & $(0.62,0.15)$ & $(0.45,0.22)$ & $(0.56,0.16)$ \\
\hline Long_Negative & $R O A \preceq L$ & $(0.65,0.26)$ & $(0.57,0.26)$ & $(0.54,0.26)$ \\
\hline Long_Negative & 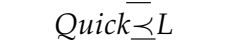 & $(0.56,0.36)$ & $(0.54,0.41)$ & $(0.52,0.34)$ \\
\hline Long_Negative & Inventory $\preceq M$ & $(0.65,0.31)$ & $(0.58,0.31)$ & $(0.57,0.30)$ \\
\hline Long_Negative & Tasset_turn $\preceq M$ & $(0.65,0.26)$ & $(0.59,0.28)$ & $(0.48,0.26)$ \\
\hline Short_Positive & LongCap $\succeq \bar{M}$ & $(0.13,0.13)$ & $(0.11,0.12)$ & $(0.13,0.13)$ \\
\hline Short_Positive & 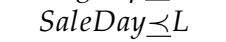 & $(0.81,0.14)$ & $(0.52,0.15)$ & $(0.39,0.15)$ \\
\hline Short_Positive & Fasset_turn $\succeq H$ & $(0.75,0.20)$ & $(0.65,0.20)$ & $(0.51,0.20)$ \\
\hline Short_Positive & $C \bar{F} \succeq H^{-}$ & $(0.81,0.19)$ & $(0.60,0.15)$ & $(0.58,0.19)$ \\
\hline Short_Positive & $N e t \bar{P} \succeq H$ & $(0.73,0.27)$ & $(0.56,0.20)$ & $(0.64,0.27)$ \\
\hline Short_Positive & $C F \_r e i n \bar{v} \succ H$ & $(0.14,0.12)$ & $(0.13,0.11)$ & $(0.14,0.13)$ \\
\hline Short_Negative & SaleDay $\bar{t}$ & $(0.74,0.24)$ & $(0.65,0.24)$ & $(0.48,0.28)$ \\
\hline Short_Negative & Tasset_turn $\preceq M$ & $(0.69,0.27)$ & $(0.63,0.27)$ & $(0.46,0.27)$ \\
\hline Short_Negative & CF_reinv $\overline{\preceq L}$ & $(0.16,0.16)$ & $(0.13,0.14)$ & $(0.16,0.16)$ \\
\hline Short_Negative & ARturn $\preceq M$ & $(0.64,0.36)$ & $(0.58,0.36)$ & $(0.49,0.36)$ \\
\hline Short_Negative & Inventory $\preceq M$ & $(0.58,0.38)$ & $(0.54,0.34)$ & $(0.53,0.39)$ \\
\hline Short_Negative & Fasset_turn $\preceq L$ & $(0.73,0.25)$ & $(0.57,0.25)$ & $(0.49,0.29)$ \\
\hline Short_Negative & $N e t P \preceq L$ & $(0.72,0.22)$ & $(0.59,0.19)$ & $(0.49,0.27)$ \\
\hline
\end{tabular}

${ }^{1}$ It denotes the averaged opinions of the DMs, and $\left(\mu_{j}, \omega_{j}\right)=(0.76,0.21)$ denotes the averaged IFS assessment of Project 1 on the requirement "Tasset_turn $\succeq H$ " for the long-term.

\section{References}

1. Black, A.; Fraser, P. Stock Market Short-Termism-An International Perspective. J. Multinatl. Financ. Manag. 2002, 12, 135-158. [CrossRef]

2. Gigler, F.; Kanodia, C.; Sapra, H.; Venugopalan, R. How Frequent Financial Reporting Can Cause Managerial Short-Termism: An Analysis of the Costs and Benefits of Increasing Reporting Frequency. J. Account. Res. 2014, 52, 357-387. [CrossRef]

3. Laverty, K.J. Economic "Short-Termism": The Debate, the Unresolved Issues, and the Implications for Management Practice and Research. Acad. Manag. Rev. 1996, 21, 825-860.

4. Laverty, K.J. Managerial Myopia or Systemic Short-Termism? The Importance of Managerial Systems in Valuing the Long Term. Manag. Decis. 2004, 42, 949-962. [CrossRef]

5. Brochet, F.; Loumioti, M.; Serafeim, G. Speaking of the Short-term: Disclosure Horizon and Managerial Myopia. Rev. Account. Stud. 2015, 20, 1122-1163. [CrossRef]

6. Hughes, A. Short-Termism, Impatient Capital and Finance for Manufacturing Innovation in UK; Centre for Business Research, University of Cambridge: Cambridge, UK, 2014.

7. Collis, J.; Jarvis, R.; Page, M. SMEs, Financial Reporting and Trade Credit: An International Study; Certified Accountants Educational Trust (London): London, UK, 2013.

8. Latham, S.; Braun, M. Does Short-Termism Influence Firm Innovation? An Examination of S\&P 500 Firms, 1990-2003. J. Manag. Issues 2010, 22, 368-382.

9. Grinyer, J.; Russell, A.; Collison, D. Evidence of Managerial Short-Termism in the UK. Br. J. Manag. 1998, 9 , 13-22. [CrossRef]

10. Atanassov, K.T. Intuitionistic Fuzzy Sets. Fuzzy Sets Syst. 1986, 20, 87-96. [CrossRef]

11. Li, D.F. Multiattribute Decision Making Method Based on Generalized OWA Operators with Intuitionistic Fuzzy Sets. Expert Syst. Appl. 2010, 37, 8673-8678. [CrossRef]

12. Deli, I.; Çağman, N. Intuitionistic Fuzzy Parameterized Soft Set Theory and Its Decision Making. Appl. Soft Comput. 2015, 28, 109-113. [CrossRef]

13. Pawlak, Z. Rough Sets. Int. J. Comput. Inf. Sci. 1982, 11, 341-356. [CrossRef]

14. Greco, S.; Matarazzo, B.; Slowinski, R. Rough Approximation of a Preference Relation by Dominance Relations. Eur. J. Oper. Res. 1999, 117, 63-83. [CrossRef]

15. Greco, S.; Matarazzo, B.; Slowinski, R. Rough Sets Methodology for Sorting Problems in Presence of Multiple Attributes and Criteria. Eur. J. Oper. Res. 2002, 138, 247-259. [CrossRef] 
16. Błaszczyński, J.; Greco, S.; Słowiński, R. Multi-Criteria Classification-A New Scheme for Application of Dominance-Based Decision Rules. Eur. J. Oper. Res. 2007, 181, 1030-1044. [CrossRef]

17. Błaszczyński, J.; Greco, S.; Słowiński, R.; Szeląg, M. Monotonic Variable Consistency Rough Set Approaches. Int. J. Approx. Reason. 2009, 50, 979-999. [CrossRef]

18. Błaszczyński, J.; Słowiński, R.; Szeląg, M. Sequential Covering Rule Induction Algorithm for Variable Consistency Rough Set Approaches. Inf. Sci. 2011, 181, 987-1002. [CrossRef]

19. Słowiński, R.; Greco, S.; Matarazzo, B. Rough-Set-Based Decision Support. Search Methodol. 2014. [CrossRef]

20. Shen, K.Y.; Tzeng, G.H. DRSA-Based Neuro-Fuzzy Inference Systems for the Financial Performance Prediction of Commercial Banks. Int. J. Fuzzy Syst. 2014, 16, 173-183.

21. Shen, K.Y.; Tzeng, G.H. A Decision Rule-Based Soft Computing Model for Supporting Financial Performance Improvement of the Banking Industry. Soft Comput. 2015, 19, 859-874. [CrossRef]

22. Shen, K.Y.; Tzeng, G.H. Combined Soft Computing Model for Value Stock Selection Based on Fundamental Analysis. Appl. Soft Comput. 2015, 37, 142-155. [CrossRef]

23. Shen, K.Y.; Tzeng, G.H. A New Approach and Insightful Financial Diagnoses for the IT Industry Based on a Hybrid MADM Model. Knowl. Based Syst. 2015, 85, 112-130. [CrossRef]

24. Shen, K.Y.; Tzeng, G.H. Combining DRSA Decision-Rules with FCA-Based DANP Evaluation for Financial Performance Improvements. Technol. Econ. Dev. Econ. 2015, 22, 685-714. [CrossRef]

25. Shen, K.Y.; Tzeng, G.H. Contextual Improvement Planning by Fuzzy-Rough Machine Learning: A Novel Bipolar Approach for Business Analytics. Int. J. Fuzzy Syst. 2016, 18, 940-955. [CrossRef]

26. Shen, K.Y.; Tzeng, G.H. A Novel Bipolar MCDM Model Using Rough Sets and Three-Way Decisions for Decision Aids. In Proceedings of the 2016 Joint 8th International Conference on Soft Computer and Intelligent Systems (SCIS) and 17th International Symposium on Advanced Intelligent Systems (ISIS), Sapporo, Japan, 25-28 August 2016; pp. 53-58.

27. Atanassov, K.T. More on intuitionistic fuzzy sets. Fuzzy Sets Syst. 1989, 33, 37-45. [CrossRef]

28. Li, D.F. Multiattribute Decision Making Models and Methods Using Intuitionistic Fuzzy Sets. J. Comput. Syst. Sci. 2005, 70, 73-85. [CrossRef]

29. Taiwan Economic Journal (TEJ). Available online: http://www.tej.com.tw/twsite/ (accessed on 5 June 2016).

30. Taiwan Stock Exchange (TSE). Available online: http://www.twse.com.tw/en/ (accessed on 1 June 2016).

31. Yager, R.R. OWA Aggregation of Intuitionistic Fuzzy Sets. Int. J. Gen. Syst. 2009, 38, 617-641. [CrossRef]

32. Li, D.F. Decision and Game Theory in Management with Intuitionistic Fuzzy Sets; Springer: Berlin, Germany, 2014.

33. Shen, K.Y.; Hu, S.K.; Tzeng, G.H. Financial Modeling and Improvement Planning for the Life Insurance Industry by Using a Rough Knowledge Based Hybrid MCDM Model. Inf. Sci. 2017, 375, 296-313. [CrossRef]

34. Zhang, X.; Li, X. A Semantic Study of the First-Order Predicate Logic with Uncertainty Involved. Fuzzy Optim. Decis. Mak. 2014, 13, 357-367. [CrossRef]

35. Opricovic, S.; Tzeng, G.H. Compromise Solution by MCDM Methods: A Comparative Analysis of VIKOR and TOPSIS. Eur. J. Oper.Res. 2004, 156, 445-455. [CrossRef]

36. Opricovic, S.; Tzeng, G.H. Extended VIKOR Method in Comparison with Outranking Methods. Eur. J. Oper. Res. 2007, 178, 514-529. [CrossRef]

37. Shen, K.Y.; Yan, M.R.; Tzeng, G.H. Combining VIKOR-DANP Model for Glamor Stock Selection and Stock Performance Improvement. Knowl. Based Syst. 2014, 58, 86-97. [CrossRef]

38. Yu, P.L. A Class of Solutions for Group Decision Problems. Manag. Sci. 1973, 19, 936-946. [CrossRef]

39. Zeleny, M. Multiple Criteria Decision Making; McGraw-Hill: New York, NY, USA, 1982.

(C) 2017 by the author. Licensee MDPI, Basel, Switzerland. This article is an open access article distributed under the terms and conditions of the Creative Commons Attribution (CC BY) license (http:/ / creativecommons.org/licenses/by/4.0/). 